\title{
One for All? Hitting Multiple Alzheimer's Disease Targets with One Drug
}

\author{
Rebecca E. Hughes ${ }^{1}$, Katarina Nikolic ${ }^{2}$ and Rona R. Ramsay ${ }^{1 *}$ \\ ${ }^{1}$ School of Biology, BMS Building, University of St Andrews, St Andrews, UK, ${ }^{2}$ Department of Pharmaceutical Chemistry, \\ Faculty of Pharmacy, University of Belgrade, Belgrade, Serbia
}

\section{HIGHLIGHTS}

- Many AD target combinations are being explored for multi-target drug design.

- New databases and models increase the potential of computational drug design

- Liraglutide and other antidiabetics are strong candidates for repurposing to AD.

- Donecopride a dual 5-HT/AChE inhibitor shows promise in pre-clinical studies

\section{OPEN ACCESS}

Edited by:

Eero Vasar,

University of Tartu, Estonia

Reviewed by:

John J. Wagner,

University of Georgia, USA

Min-Yu Sun,

Washington University in St. Louis,

Elizabeth Yuriev,

Monash University, Australia

${ }^{*}$ Correspondence:

Rona R. Ramsay

rrr@st-andrews.ac.uk

Specialty section:

This article was submitted to

Neuropharmacology,

a section of the journal

Frontiers in Neuroscience

Received: 22 February 2016

Accepted: 06 April 2016

Published: 25 April 2016

Citation:

Hughes RE, Nikolic K and Ramsay RR

(2016) One for All? Hitting Multiple

Alzheimer's Disease Targets with One

Drug. Front. Neurosci. 10:177.

doi: 10.3389/fnins.2016.00177
Alzheimer's Disease is a complex and multifactorial disease for which the mechanism is still not fully understood. As new insights into disease progression are discovered, new drugs must be designed to target those aspects of the disease that cause neuronal damage rather than just the symptoms currently addressed by single target drugs. It is becoming possible to target several aspects of the disease pathology at once using multi-target drugs (MTDs). Intended as an introduction for non-experts, this review describes the key MTD design approaches, namely structure-based, in silico, and data-mining, to evaluate what is preventing compounds progressing through the clinic to the market. Repurposing current drugs using their off-target effects reduces the cost of development, time to launch, and the uncertainty associated with safety and pharmacokinetics. The most promising drugs currently being investigated for repurposing to Alzheimer's Disease are rasagiline, originally developed for the treatment of Parkinson's Disease, and liraglutide, an antidiabetic. Rational drug design can combine pharmacophores of multiple drugs, systematically change functional groups, and rank them by virtual screening. Hits confirmed experimentally are rationally modified to generate an effective multi-potent lead compound. Examples from this approach are ASS234 with properties similar to rasagiline, and donecopride, a hybrid of an acetylcholinesterase inhibitor and a $5-\mathrm{HT}_{4}$ receptor agonist with pro-cognitive effects. Exploiting these interdisciplinary approaches, public-private collaborative lead factories promise faster delivery of new drugs to the clinic.

Keywords: multi-target drugs, Alzheimer's Disease, in silico, datamining, rational drug design, repurposing

Abbreviations: AD, Alzheimer's Disease; AChE, acetylcholinesterase; $\mathrm{A} \beta$, amyloid beta; $\mathrm{MAO}$, monoamine oxidase; MTD, multi-target drug; N-methyl-D-aspartate (NMDA receptor; GABA, gamma-aminobutyric acid; 5 - $\mathrm{HT}_{4} \mathrm{R}$, serotonin (5-HT) receptor type 4; Glucagon-like peptide 1 (GLP-1); BBB, blood brain barrier. 


\section{INTRODUCTION}

Current therapies available for the treatment of Alzheimer's Disease (AD) show limited ability to modify the disease. To date the focus for $\mathrm{AD}$ has been on the depletion of acetylcholine, but $\mathrm{AD}$ is a complex multifactorial disease with diverse clinical symptoms. $\mathrm{AD}$ causes the gradual onset of multiple cognitive deficits, affecting language, episodic memory and attention (Karran et al., 2011). The disease pathology includes extracellular amyloid beta $(\mathrm{A} \beta)$ plaques, intracellular neurofibrillary tangles, inflammation, oxidative stress, iron dysregulation and ultimately neuronal cell death (Carreiras et al., 2013). It is accepted that multifactorial diseases require the simultaneous modulation of multiple targets to manage the course of disease progression (Cavalli et al., 2008), leading to growth in multi-target drug (MTD) design (Hopkins, 2008). This review focuses on possible targets, their combinations, and the three main approaches to designing MTDs: structure-based design, data mining/repurposing, and in silico screening. The application of rational drug design to MTDs is difficult but with the recent advances in experimental and computational approaches, a combined approach harnessing the best attributes of each method should ultimately deliver success in the future.

\section{TARGETS AND CURRENT THERAPIES; LIMITATIONS IN ALZHEIMER'S DISEASE}

The multifactorial nature of $\mathrm{AD}$ means there are many possible therapeutic targets. Current monotherapeutic treatments focus mainly on acetylcholinesterase (AChE) inhibition due to the early cholinergic hypothesis that cognitive dysfunctions of $\mathrm{AD}$ may be attributed to decreased neurotransmission at cholinergic synapses as a result of neuronal cell death (Bartus et al., 1982). AChE therapies provide symptomatic relief, but fail to reverse disease progression (Wilkinson et al., 2004; Deardorff et al., 2015), although recent work suggests that donepezil (Table 1) may enhance $A \beta$ clearance (Mohamed et al., 2015). The amyloid hypothesis that the generation of toxic $A \beta$ from amyloid precursor protein (APP) and $A \beta$ aggregation result in the pathophysiological changes associated with $\mathrm{AD}$ (Figure 1) led to compounds targeting $A \beta$ (Karran et al., 2011; Eisele et al., 2015). Although small molecules can target $A \beta$ aggregation (see Table 1), the main strategy is immunotherapy, still in clinical trials (Palmer, 2011; Wisniewski and Goñi, 2014). Better understanding of protein aggregation is now available to guide therapeutic intervention on both $A \beta$ and tau aggregation (Eisele et al., 2015).

Following on from direct targeting of $\mathrm{A} \beta$, a relatively new target in $\mathrm{AD}$ is the $\beta$-secretase (BACE-1) enzyme. Inhibition of this protease BACE-1 should reduce the levels of $A \beta$ in the brain (Vassar, 2014). BACE-1 inhibitors in clinical trials include AZD3293 in phase II/III (NCT02245737) and MK8931 (verubecestat) in phase III (NCT01953601). While these drugs show promise, there are potential complications from a possible role in synaptic function (Kandalepas and Vassar, 2014) and increased memory impairment and seizures in BACE-1 -/- mice (Hu et al., 2016).

Another major enzyme target, monoamine oxidase (MAO) is inhibited in Parkinson's Disease (PD) to spare the neurotransmitters depleted by neuronal death. The PD drug, rasagiline (see below), is a MAO-B inhibitor in clinical trials for AD (Weinreb et al., 2010).

$\mathrm{N}$-methyl-D-aspartate (NMDA) is a glutamate receptor and is the only other target besides AChE for which a therapy has been approved (Anand et al., 2014). NMDA receptors are overstimulated in $\mathrm{AD}$ brains due to excessive release of glutamate from neurons. This causes high levels of calcium ion influx and activation of enzymes that can cause neuronal cell death (Zheng et al., 2014). NMDA receptors have also been linked to tau hyper-phosphorylation and A $\beta$ toxicity (Couratier et al., 1996). Memantine is the only approved NMDA receptor antagonist for the treatment of moderate to severe AD (Lipton, 2006).

Other receptors being explored are the 5-hydroxytryptamine (5-HT) serotonin receptors, in particular subtype $4\left(5-\mathrm{HT}_{4} \mathrm{R}\right)$ that is involved in mood, memory, and learning. 5- $\mathrm{HT}_{4} \mathrm{R}$ has been linked to memory deficits such as those seen in $\mathrm{AD}$ (Cho and $\mathrm{Hu}, 2007$; Lezoualc'h, 2007; Russo et al., 2009). Stimulation causes release of $\mathrm{ACh}$ and increases other neurotransmitters (Licht et al., 2010).

Inhibition of these targets individually with current drugs (Table 1) has been ineffective at reversing the progression of the disease. A possible answer lies in a polypharmacological approach to modify activities of several of these targets simultaneously, particularly those associated with the progression of the disease. MTDs developed for $\mathrm{AD}$ have modified two or more of known targets (cholinesterases, MAOs, acetylcholine receptors, serotonin receptors) or have properties thought to retard disease progression, such as metal chelation, antioxidant or anti-inflammatory activity, or prevention of $A \beta$ or tau aggregation. Ligands for combinations of drug targets should be evaluated against disease progression to define optimal target combinations.

\section{DATAMINING AND REPURPOSING}

Repurposing is the development of existing or abandoned drugs for new indications (Boguski et al., 2009), related to the original purpose or after off-target effects are identified by datamining. Repurposing reduces the time to launch, cost of development, and the uncertainty associated with safety and pharmacokinetics (Kim, 2015).

Datamining is a way of using pre-existing knowledge about molecules and applying it to develop new drugs (Sirota et al., 2011; Corbett et al., 2012, 2013). For example, clinical data can be used to identify unanticipated benefits in side effects seen in clinical trials, allowing the early repurposing of therapies (Loging et al., 2011). The most promising drug currently being investigated for repurposing is rasagiline, a selective, irreversible MAO-B inhibitor for the treatment of PD (Youdim et al., $1995,2001)$. The repurposing to $\mathrm{AD}$ stems from the ability of rasagiline to regulate the non-amyloidogenic processing of 
TABLE 1 | Targets, drugs, and new multi-target ligands to combat Alzheimer's Disease (AD).

\begin{tabular}{|c|c|c|c|}
\hline Targets & Drug name & Structure & Comment \\
\hline \multicolumn{4}{|c|}{ (A) APPROVED DRUGS } \\
\hline \multirow[t]{3}{*}{ Acetylcholinesterase } & Donepezil & & Approved drug \\
\hline & Rivastigmine & & Approved drug \\
\hline & Tacrine & & Withdrawn \\
\hline Monoamine oxidase & Rasagiline & & $\begin{array}{l}\text { Approved for PD } \\
\text { Phase II for } A D\end{array}$ \\
\hline $\begin{array}{l}\text { Cholinesterase } \\
A \beta \text { aggregation }\end{array}$ & Donepezil & & Ozer et al., 2013 \\
\hline $\begin{array}{l}\text { AChE } \\
\text { BACE-1 }\end{array}$ & $\begin{array}{l}\text { Huprine } \\
\text { Tacrine }\end{array}$ & & Galdeano et al., 2012 \\
\hline
\end{tabular}


TABLE 1 | Continued

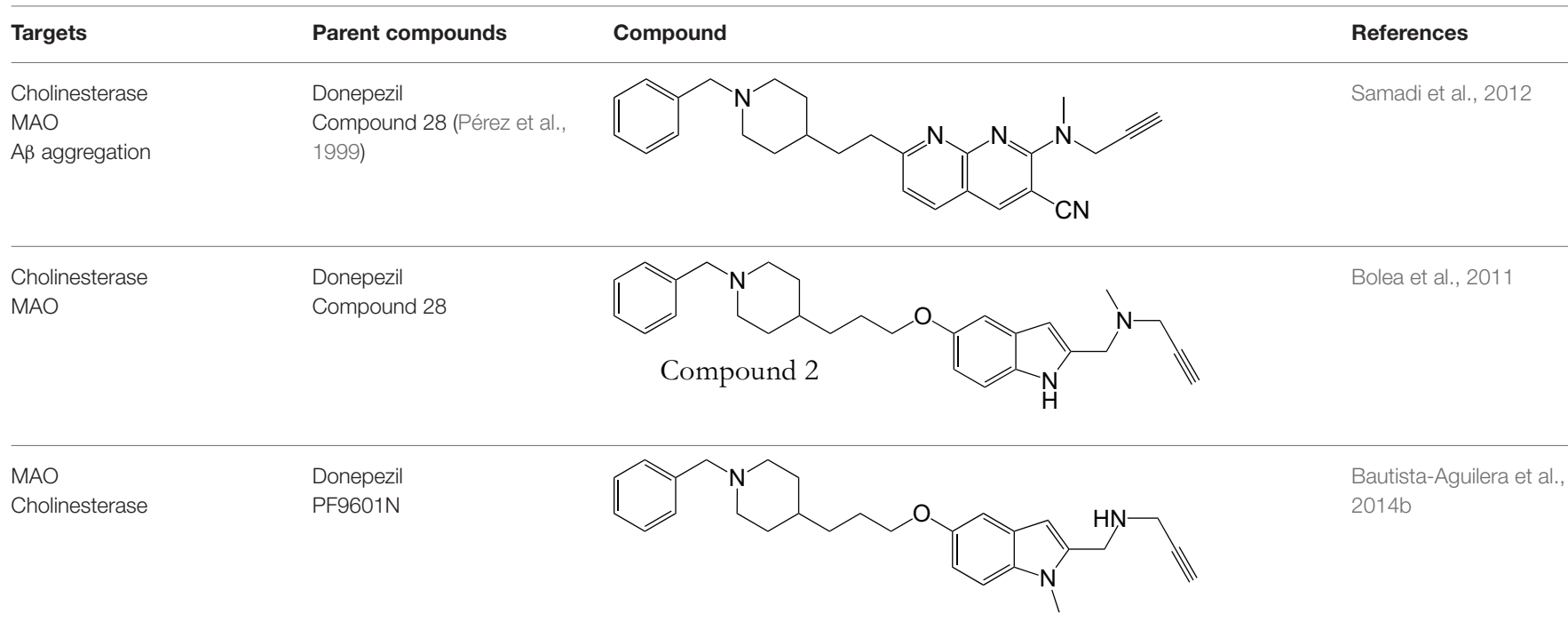

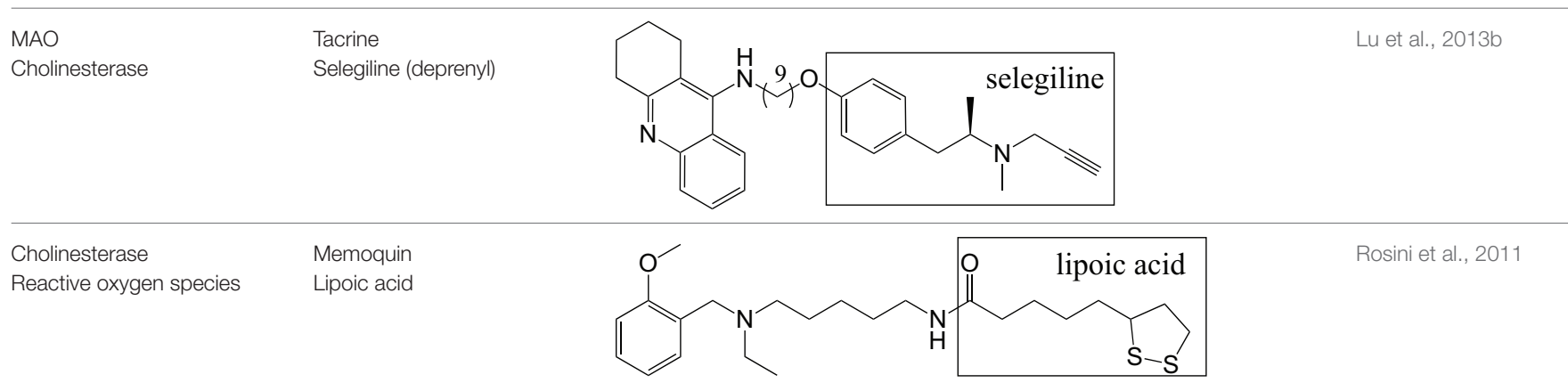

MAO Resveratrol
Metal chelator
A $\beta$ aggregation
Cholinesterase<smiles>Cc1ccc(/C=C/c2ccc(NCc3cc(N(C)C)ccc3O)cc2)cc1O</smiles>

Lu et al., 2013a

APP (Yogev-Falach et al., 2003; Bar-Am et al., 2004). Rasagiline also shows neuroprotective activity due to the propargylamine moiety that activates $\mathrm{Bcl}-2$ and down-regulates the Bax proteins (Youdim et al., 2005). It is now in Phase II trial for the treatment of AD (www.clinicaltrials.gov/ct2/show/NCT02359552).

Natural products provide another potential source of MTDs (Ji et al., 2009; Prati et al., 2014). Datamining could harness their potential and then synthetic analogs and derivatives created to enhance their activity (Agis-Torres et al., 2014). Huperzine A, a dietary supplement in China, is an AChE inhibitor (Xing et al., 2014) seemingly with beneficial effects on cognitive function and daily living in $\mathrm{AD}$ patients, but the clinical trials to date have poor methodological approaches and so results are inconclusive (Xu et al., 1995; Rafii et al., 2011). Synthetic derivatives like huprine X and huprine-tacrine hybrids have been developed to improve on the potency and efficacy of huperzine A (Galdeano et al., 2012).

One promising repurposing area is from diabetes to $\mathrm{AD}$, first considered because type 2 diabetes is a risk factor for AD (Schrijvers et al., 2010). Insulin signaling is impaired in the brains of Alzheimer's patients (Moloney et al., 2010) so several aspects of insulin signaling and regulation have been targeted. For example, Phase II clinical trials of intranasal insulin administration showed improved biomarkers for early $\mathrm{AD}$ including amyloid and tau indicators in cerebrospinal 


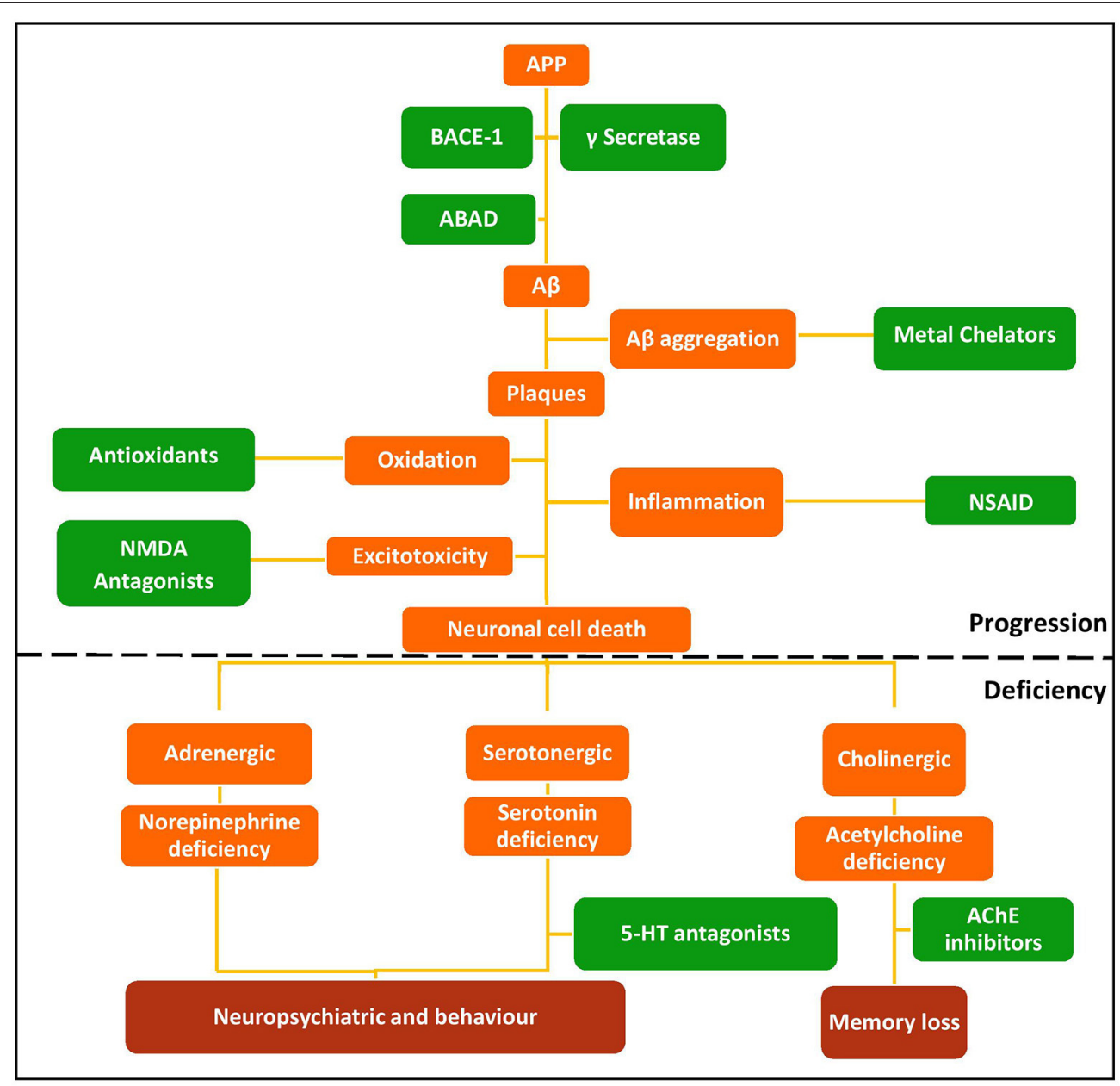

FIGURE 1 | Schematic of the amyloid hypothesis, the targets associated with AD, and potential drug intervention strategies. Red, disease outcomes; Orange, Pathology; Green, Intervention strategies and drug classes.

fluid (CSF) (Craft et al., 2012). Long-lasting glucagon-like peptide 1 (GLP-1) analogs that promote the secretion of insulin are also in clinical trials. Three GLP-1 analogs with potential therapeutic value in AD (Corbett et al., 2012; Hölscher, 2014), have shown in vivo benefits in mouse AD models (Gengler et al., 2012). Two of these are Exendin-4 in Phase II clinical trial (See www.clinicaltrials.gov/ct/show/NCT01255163) and Liraglutide, a GLP-1 receptor agonist. Liraglutide crosses the blood brain barrier (BBB) in animal models (Hunter and Hölscher, 2012). It decreases intracellular APP, $A \beta$, and $\mathrm{Fe}^{2+}$ related neurodegeneration, but also improves synaptic plasticity and cognitive function, reducing AD pathology (McClean et al., 2011; McClean and Hölscher, 2014).

\section{DATABASES AND OPEN-ACCESS MINING}

The construction of $\mathrm{AD}$ knowledge bases will facilitate the repurposing of drugs and our understanding of the neurosignaling pathways involved. One such example is AlzPlatform, an $\mathrm{AD}$ domain-specific chemogenomics database allowing the identification of off-target effects and the repurposing of compounds (Liu et al., 2014). AlzPlatform contains the established computational algorithm TargetHunter, which is an in silico target identification tool for small molecules (Wang et al., 2013).

While there is a wealth of open access chemical information available to aid repurposing of FDA approved drugs, compound libraries held by pharmaceutical companies are, for the most part, unavailable. Datamining to find possible targets for these compounds could prove fruitful. An open-innovation drug-repositioning project between AstraZeneca and the Medical Research Council (http://www.labtalk.astrazeneca. com/hot-topics/open-innovation-in-drug-repositioning/) has started and the National Center for Advancing Translational Sciences (NCATS) has created a similar collaboration with 8 pharmaceutical companies. One of the compounds from this program is the Src tyrosine kinase inhibitor, AZD0530 (Saracatinib), being repurposed for the treatment of $\mathrm{AD}$ (Larson et al., 2012; Nygaard et al., 2014). The European Lead 
Factory (www.europeanleadfactory.eu) is another initiative set up to allow sharing of commercial compound libraries via collaborative public-private partnerships. The compound library, a pool of 30 partner libraries, provides a collection of over 500,000 compounds available for academic groups and pharmaceutical companies to screen experimentally against their chosen targets with great potential to generate new therapeutics.

\section{RATIONAL DRUG DESIGN}

Rational drug design is a traditional method for drug development based on structure-function analysis. Successful rational drug design requires the logical and systematic changing of substituents to modify the properties of a compound to reach the desired effect. When applied to MTD design, it means combining pharmacophores of multiple drugs to give complex combinations, then compensating for any disadvantage to the individual targets.

M30, a brain-permeable iron chelator and brain selective MAO inhibitor, was designed on the rationale that MAO and iron are elevated in the brains of $\mathrm{AD}$ patients, and this leads to oxidative stress and neurodegeneration (Youdim, 2006). The MAO inhibition is due to the propargylamine of the FDAapproved anti-PD drug rasagiline (Youdim, 2013). The iron chelating activity comes from the prototype iron chelator VK28 (Zheng et al., 2014). M30 irreversibly inhibits both MAO-A and -B with $\mathrm{IC}_{50}$ values of $37 \pm 2 \mathrm{nM}$ and $57 \pm 1 \mathrm{nM}$ respectively, less selective than rasagiline ( $412 \mathrm{nM}$ and $4.4 \mathrm{nM}$, respectively) (Zheng et al., 2005). It also regulates APP via its iron chelating ability since APP is a metalloprotein with an iron responsive element in the $5^{\prime}$ untranslated region (UTR) (Youdim, 2013). Therefore, it has a direct effect on $A \beta$ levels.

To reduce the possibility of adverse effects of metal chelation in the periphery, a second-generation molecule and prodrug, M30D, was designed from tacrine, rivastigmine, and rasagiline (Zheng et al., 2010a,b, 2014). It was 3-fold more potent against MAO-A ( $\mathrm{IC}_{50}$ of $7.7 \mathrm{nM}$ ) than the parental molecule, retaining the same MAO-B inhibition (Zheng et al., 2014). It is metabolized to the active chelator form M30 by AChE and inhibits AChE with an $\mathrm{IC}_{50}$ of $500 \mathrm{nM}$ in rat brain homogenates. With these characteristics, M30D is the first site-directed metal chelator with the potential to treat $\mathrm{AD}$.

A similar MTD is ASS234 composed from donepezil and the propargylamine $\mathrm{PF} 9601 \mathrm{~N}$. It binds to all the $\mathrm{AChE} / \mathrm{BuChE}$ and $\mathrm{MAO} \mathrm{A} / \mathrm{B}$ enzymes, shows antioxidant, neuroprotective and suitable permeability properties. In vivo, ASS234 restores scopolamine-induced cognitive impairment to the same extent as donepezil, is less toxic, and prevents $\beta$-amyloid aggregation in the cortex of AD transgenic mice (Bolea et al., 2013; del Pino et al., 2014).

Another promising structure-based MTD is donecopride. Donecopride is a structural hybrid of donepezil, an AChE inhibitor, and RS67333, a 5- $\mathrm{HT}_{4} \mathrm{R}$ agonist. RS67333 is a partial $5-\mathrm{HT}_{4} \mathrm{R}$ agonist that exerts a procognitive effect via its ability to promote cleavage of APP. RS67333 is structurally similar to donepezil, so it was postulated that it might inhibit AChE. It was indeed a submicromolar AChE inhibitor (Lecoutey et al., 2014; Rochais et al., 2015). Derivatives of RS67333 were then synthesized to improve the AChE activity, from which MR31147 (donecopride) was selected for its remarkable multitarget activity in vitro, including an IC50 for AChE of $16 \mathrm{nM}$ (Lecoutey et al., 2014). Donecopride crosses BBB, has a nontoxic profile, and exerts a procognitive effect in vivo (Lecoutey et al., 2014). It will be interesting to see how this promising molecule progresses since $5-\mathrm{HT}_{4}$ targeted therapies have been less commonly explored for $\mathrm{AD}$.

These examples show how methodical rational drug design and experimental screening can be used to generate promising MTD candidates for the treatment of AD.

\section{IN SILICO SCREENING}

Rational drug design is currently the approach of choice for MTD design but it is labor intensive, so there is a need for more in silico screening to reduce costs and accelerate progress. New computer-based approaches for in silico screening (Ekins et al., 2007a; Wang et al., 2013), such as quantitative structure-activity relationships, molecular modeling approaches, machine learning, data mining, and data analysis tools, use in vitro data to generate predictive models. Such models are very useful in the discovery and optimization of novel ligands with enhanced affinity to a drug target, as well as for optimization of physicochemical and pharmacokinetic properties of the drug candidates. Several of these in silico methods will be evaluated here in the context of selected MTD examples.

Virtual ligand screening is an alternative to experimental high throughput screening (Ekins et al., 2007a). It can be used to screen whole databases of molecules and rank them based on their probability of binding to a drug target. The highest-ranking molecules can then be taken through to an experimental stage to confirm the hits and determine the most promising leads. Virtual screening can be either ligand based, where a diverse set of ligands are analyzed to build up a pharmacophore to score the screen against, or it can be structure-based, where molecules are docked onto the target and scored based on their likely affinity for the target. Quantitative structure-activity relationships (QSAR) is a form of ligand-based virtual screening but it uses a series of logicbased rules describing the chemical properties and substructures linked to activity to screen a database of molecules (Ekins et al., 2007b).

Recently a virtual ligand screen (Bautista-Aguilera et al., 2014a) was used for lead optimization of two donepezil hybrid compounds shown previously to inhibit MAO-A, MAO-B, AChE, and BuChE (Bolea et al., 2011). The 3D-QSAR analysis was carried out both to explain the binding of these compounds to the active sites of the enzymes and to predict substitutions that would increase binding. The QSAR model was used to generate 19 new molecules with substitutions predicted to increase the activity against MAOs and ChEs. The predicted IC50 values suggested that $\mathrm{N}$-[(5-benzyloxy-1-methyl-1-H-indol-2yl)methyl]-N-methylprop-2-yn-1-amine (compound 2) would 
be the most potent inhibitor of all four enzymes with values in the nanomolar range for MAO-A, MAO-B, and AChE, while BuChE was predicted at $1.3 \mu \mathrm{M}$. The experimental results showed that only 7 of the 19 compounds were active against all four enzymes, which demonstrates how difficult it can be to get activity against four enzymes in one molecule. However, as predicted, compound 2 was the most potent against all four enzymes, confirming the quality of the 3D-pharmacophores. Thus, in silico screening can be used to modify a lead compound and generate effective multi-potent inhibitors (Bautista-Aguilera et al., 2014a).

Another option, rather than start from a lead molecule, is to use pharmacophore models to screen existing compound databases with the aim of generating hits against multiple targets. This approach has been used to identify dual inhibitors of BACE-1 and AChE using a combination of virtual screening and molecular docking of compounds from three compound databases. The strategy adopted follows a sequential screening model where the databases were screened in parallel against the two targets sequentially before filters were applied to select for compounds with desirable properties. Finally, docking of the chosen compounds led to 8 compounds from the original 501,799 that fit all the given criteria (Tyagi et al., 2010).

Importantly, in silico screening allows the early filtering of compounds based on properties, such as BBB permeability, which can reduce late stage attrition. However, screening sequentially means that compounds that fall below the cut-off criteria in the first round are not screened against the second target. To avoid loss of potential candidates, screening against the targets in parallel is essential (Steindl et al., 2006).

\section{CONCLUDING REMARKS}

Over the past decade, there has been a substantial research effort to design MTDs for the treatment of AD. This focus on MTDs is aided by the understanding that $\mathrm{AD}$ is a complex and multifactorial disease affecting many interlinked pathological pathways. The lack of efficacy seen with the single target approach is compelling evidence that we needed to rethink the paradigm of drug design to treat these multifactorial diseases. MTD design offers a promising avenue for the progression of $\mathrm{AD}$ therapeutic intervention and could ultimately lead to a drug with the ability to reverse disease progression.

While there are many targets for disease-modifying drugs, it remains to be seen which combinations will prove efficacious. It seems logical that in order to reverse disease progression, we must target those aspects of the disease that cause neuronal

\section{REFERENCES}

Agis-Torres, A., Sölhuber, M., Fernandez, M., and Sanchez-Montero, J. M. (2014). Multi-target-directed ligands and other therapeutic strategies in the search of a real solution for alzheimer's disease. Curr. Neuropharmacol. 12, 2-36. doi: 10.2174/1570159X113116660047

Anand, R., Gill, K. D., and Mahdi, A. A. (2014). Therapeutics of Alzheimer's disease: past, present and future. Neuropharmacology 76, 27-50. doi: 10.1016/j.neuropharm.2013.07.004 damage, such as $A \beta$ and oxidative damage, rather than just targeting the breakdown enzymes to alleviate the deficiencies caused by cell death. Of course, targeting a combination of both would relieve symptoms and prevent further neuronal loss.

In terms of the approach to MTD design, an integrated approach using a combination of in silico and rational drug design should reduce the cost of high throughput screening and progress discovery more rapidly. The MTD approach is also being used to combat the development of resistance to antimicrobials. MBX-500 has been designed as a hybrid of two classes of antibiotics, fluoroquinolone and anilinouracil, for the treatment of Clostridium difficile infections (Butler et al., 2012). TD-1792, a cephalosporin-vancomycin hybrid, has passed a phase II clinical trial for gram-positive skin infections (Stryjewski et al., 2012). While MTD design is in its infancy in the world of antibiotics, there is evidence that it could prove promising here too (East and Silver, 2013; Oldfield and Feng, 2014).

Overall, MTD design is a promising approach to modern medicines for complex diseases. Whether drugs will come from repurposing, rational drug design, in silico screening, or a combination approach we cannot predict, but the race is on to develop the first approved MTD capable of reversing AD pathology.

\section{AUTHOR CONTRIBUTIONS}

$\mathrm{REH}$ reviewed the literature and wrote the draft. All authors contributed to the conception, interpretation, and critical revision of the work. All authors have approved the final version of this review of current literature.

\section{FUNDING}

The authors thank COST Action CM1103 for the productive collaborations that inspired this work and for open access funding.

\section{ACKNOWLEDGMENTS}

The authors thank the participants in COST Action CM1103 "Structure-based drug design for diagnosis and treatment of neurological diseases: dissecting and modulating complex function in the monoaminergic systems of the brain" for productive collaborations and COST for funding open access publication. 
QSAR analysis, molecular modeling and ADMET of novel donepezil-indolyl hybrids as multipotent cholinesterase/monoamine oxidase inhibitors for the potential treatment of Alzheimer's disease. Eur. J. Med. Chem. 75, 82-95. doi: 10.1016/j.ejmech.2013.12.028

Bautista-Aguilera, O. M., Samadi, A., Chioua, M., Nikolic, K., Filipic, S., Agbaba, D., et al. (2014b). N-Methyl-N-((1-methyl-5-(3-(1-(2-methylbenzyl)piperidin4yl)propoxy)-1H- indol-2-yl)methyl)prop-2-yn-1-amine, a new cholinesterase and monoamine oxidase dual. J. Med. Chem. 57, 10455-10463. doi: 10.1021/jm501501a

Boguski, M. S., Mandl, K. D., and Sukhatme, V. P. (2009). Repurposing with a difference. Science 324, 1394-1395. doi: 10.1126/science.1169920

Bolea, I., Gella, A., Monjas, L., Perez, C., Rodriguez-Franco, M. I., MarcoContelles, J., et al. (2013). Multipotent, permeable drug ASS234 inhibits A beta aggregation, possesses antioxidant properties and protects from A beta-induced apoptosis in vitro. Curr. Alzheimer Res. 10, 797-808. doi: $10.2174 / 15672050113109990151$

Bolea, I., Juarez-Jimenez, J., de los Rios, C., Chioua, M., Pouplana, R., Javier Luque, F., et al. (2011). Synthesis, biological evaluation, and molecular modeling of donepezil and N- (5-(Benzyloxy)-1-methyl-1H-indol-2yl)methyl -N-methylprop-2-yn-1-ami ne hybrids as new multipotent cholinesterase/monoamine oxidase inhibitors for the treatment of Alzheimer's disease. J. Med. Chem. 54, 8251-8270. doi: 10.1021/jm2 $00853 \mathrm{t}$

Butler, M. M., Shinabarger, D. L., Citron, D. M., Kelly, C. P., Dvoskin, S., Wright, G. E., et al. (2012). MBX-500, a hybrid antibiotic with in vitro and in vivo efficacy against toxigenic clostridium difficile. Antimicrob. Agents Chemother. 56, 4786-4792. doi: 10.1128/AAC.00508-12

Carreiras, M. C., Mendes, E., Jesus Perry, M. J., Francisco, A. P., and MarcoContelles, J. (2013). The multifactorial nature of Alzheimer's disease for developing potential therapeutics. Curr. Top. Med. Chem. 13, 1745-1770. doi: $10.2174 / 15680266113139990135$

Cavalli, A., Bolognesi, M. L., Minarini, A., Rosini, M., Tumiatti, V., Recanatini, M., et al. (2008). Multi-target-directed ligands to combat neurodegenerative diseases. J. Med. Chem. 51, 347-372. doi: 10.1021/jm7009364

Cho, S., and Hu, Y. (2007). Activation of 5-HT4 receptors inhibits secretion of beta-amyloid peptides and increases neuronal survival. Exp. Neurol. 203, 274-278. doi: 10.1016/j.expneurol.2006.07.021

Corbett, A., Pickett, J., Burns, A., Corcoran, J., Dunnett, S. B., Edison, P., et al. (2012). Drug repositioning for Alzheimer's disease. Nat. Rev. Drug Discov. 11, 833-846. doi: 10.1038/nrd3869

Corbett, A., Williams, G., and Ballard, C. (2013). Drug repositioning: an opportunity to develop novel treatments for Alzheimer's disease. Pharmaceuticals 6, 1304-1321. doi: 10.3390/ph6101304

Couratier, P., Lesort, M., Sindou, P., Esclaire, F., Yardin, C., and Hugon, J. (1996). Modifications of neuronal phosphorylated tau immunoreactivity induced by NMDA toxicity. Mol. Chem. Neuropathol. 27, 259-273. doi: 10.1007/BF02815108

Craft, S., Baker, L. D., Montine, T. J., Minoshima, S., Watson, G. S., Claxton, A., et al. (2012). Intranasal insulin therapy for Alzheimer disease and amnestic mild cognitive impairment a pilot clinical trial. Arch. Neurol. 69, 29-38. doi: 10.1001/archneurol.2011.233

Deardorff, W. J., Feen, E., and Grossberg, G. T. (2015). The use of cholinesterase inhibitors across all stages of Alzheimer's disease. Drugs Aging 32, 537-547. doi: 10.1007/s40266-015-0273-X

del Pino, J., Ramos, E., Bautista-Aguilera, O. M., Marco-Contelles, J., and Romero, A. (2014). Wnt signaling pathway, a potential target for Alzheimer's disease treatment, is activated by a novel multitarget compound ASS234. CNS Neurosci. Ther. 20, 568-570. doi: 10.1111/cns.12269

East, S. P., and Silver, L. L. (2013). Multitarget ligands in antibacterial research: progress and opportunities. Expert Opin. Drug Discov. 8, 143-156. doi: 10.1517/17460441.2013.743991

Eisele, Y. S., Monteiro, C., Fearns, C., Encalada, S. E., Wiseman, R. L., Powers, E. T., et al. (2015). Targeting protein aggregation for the treatment of degenerative diseases. Nat. Rev. Drug Discov. 14, 759-780. doi: 10.1038/nrd4593

Ekins, S., Mestres, J., and Testa, B. (2007a). In silico pharmacology for drug discovery: methods for virtual ligand screening and profiling. Br. J. Pharmacol. 152, 9-20. doi: 10.1038/sj.bjp.0707305
Ekins, S., Mestres, J., and Testa, B. (2007b). In silico pharmacology for drug discovery: applications to targets and beyond. Br. J. Pharmacol. 152, 21-37. doi: 10.1038/sj.bjp.0707306

Galdeano, C., Viayna, E., Sola, I., Formosa, X., Camps, P., Badia, A., et al. (2012). Huprine-tacrine heterodimers as anti-amyloidogenic compounds of potential interest against Alzheimer's and Prion diseases. J. Med. Chem. 55, 661-669. doi: $10.1021 / \mathrm{jm} 200840 \mathrm{c}$

Gengler, S., McClean, P. L., McCurtin, R., Gault, V. A., and Hoelscher, C. (2012). Val(8)GLP-1 rescues synaptic plasticity and reduces dense core plaques in APP/PS1 mice. Neurobiol. Aging 33, 265-276. doi: 10.1016/j.neurobiolaging.2010.02.014

Hölscher, C. (2014). Central effects of GLP-1: new opportunities for treatments of neurodegenerative diseases. J. Endocrinol. 221, T31-T41. doi: 10.1530/JOE-130221

Hopkins, A. L. (2008). Network pharmacology: the next paradigm in drug discovery. Nat. Chem. Biol. 4, 682-690. doi: 10.1038/nchembio.118

$\mathrm{Hu}, \mathrm{X}$., Fan, Q., Hou, H., and Yan, R. (2016). Neurological dysfunctions associated with altered BACE1-dependent neuregulin-1 signaling. J. Neurochem. 136, 234-249. doi: 10.1111/jnc.13395

Hunter, K., and Hölscher, C. (2012). Drugs developed to treat diabetes, liraglutide and lixisenatide, cross the blood brain barrier and enhance neurogenesis. BMC Neurosci. 13:33. doi: 10.1186/1471-2202-13-33

Ji, H.-F., Li, X.-J., and Zhang, H.-Y. (2009). Natural products and drug discovery can thousands of years of ancient medical knowledge lead us to new and powerful drug combinations in the fight against cancer and dementia? EMBO Rep. 10, 194-200. doi: 10.1038/embor.2009.12

Kandalepas, P. C., and Vassar, R. (2014). The normal and pathologic roles of the Alzheimer's beta-secretase, BACE1. Curr. Alzheimer Res. 11, 441-449. doi: 10.2174/1567205011666140604122059

Karran, E., Mercken, M., and De Strooper, B. (2011). The amyloid cascade hypothesis for Alzheimer's disease: an appraisal for the development of therapeutics. Nat. Rev. Drug Discov. 10, 698-U1600. doi: 10.1038/nrd3505

Kim, T.-W. (2015). Drug repositioning approaches for the discovery of new therapeutics for Alzheimer's disease. Neurotherapeutics 12, 132-142. doi: 10.1007/s13311-014-0325-7

Larson, M., Sherman, M. A., Amar, F., Nuvolone, M., Schneider, J. A., Bennett, D. A., et al. (2012). The complex PrPc-Fyn couples human oligomeric A beta with pathological tau changes in Alzheimer's disease. J. Neurosci. 32, 16857. doi: 10.1523/JNEUROSCI.1858-12.2012

Lecoutey, C., Hedou, D., Freret, T., Giannoni, P., Gaven, F., Since, M., et al. (2014). Design of donecopride, a dual serotonin subtype 4 receptor agonist/acetylcholinesterase inhibitor with potential interest for Alzheimer's disease treatment. Proc. Natl. Acad. Sci. U.S.A. 111, E3825-E3830. doi: $10.1073 /$ pnas. 1410315111

Lezoualc'h, F. (2007). 5-HT4 receptor and Alzheimer's disease: the amyloid connection. Exp. Neurol. 205, 325-329. doi: 10.1016/j.expneurol.2007.02.001

Li, S.-Y., Wang, X.-B., and Kong, L.-Y. (2014). Design, synthesis and biological evaluation of imine resveratrol derivatives as multi-targeted agents against Alzheimer's disease. Eur. J. Med. Chem. 71, 36-45. doi: 10.1016/j.ejmech.2013.10.068

Licht, C. L., Knudsen, G. M., and Sharp, T. (2010). Effects of the 5-HT4 receptor agonist RS67333 and paroxetine on hippocampal extracellular 5-HT levels. Neurosci. Lett. 476, 58-61. doi: 10.1016/j.neulet.2010.04.002

Lipton, S. A. (2006). Paradigm shift in neuroprotection by NMDA receptor blockade: memantine and beyond. Nat. Rev. Drug Discov. 5, 160-170. doi: $10.1038 / \operatorname{nrd} 1958$

Liu, H., Wang, L., Lv, M., Pei, R., Li, P., Pei, Z., et al. (2014). AlzPlatform: an Alzheimer's disease domain-specific chemogenornics knowledgebase for polypharmacology and target identification research. J. Chem. Inf. Model. 54, 1050-1060. doi: 10.1021/ci500004h

Loging, W., Rodriguez-Esteban, R., Hill, J., Freeman, T. B., and Miglietta, J. (2011). Cheminformatic/bioinformatic analysis of large corporate databases: application to drug repurposing. Drug Discov. Today Ther. Strateg. 8, 109-116. doi: 10.1016/j.ddstr.2011.06.004

Lu, C., Guo, Y., Yan, J., Luo, Z., Luo, H.-B., Yan, M., et al. (2013a). Design, synthesis, and evaluation of multitarget-directed resveratrol derivatives for the treatment of Alzheimer's disease. J. Med. Chem. 56, 5843-5859. doi: 10.1021/jm400567s 
Lu, C., Zhou, Q., Yan, J., Du, Z., Huang, L., and Li, X. (2013b). A novel series of tacrine-selegiline hybrids with cholinesterase and monoamine oxidase inhibition activities for the treatment of Alzheimer's disease. Eur. J. Med. Chem. 62, 745-753. doi: 10.1016/j.ejmech.2013.01.039

McClean, P. L., and Hölscher, C. (2014). Liraglutide can reverse memory impairment, synaptic loss and reduce plaque load in aged APP/PS1 mice, a model of Alzheimer's disease. Neuropharmacology 76, 57-67. doi: 10.1016/j.neuropharm.2013.08.005

McClean, P. L., Parthsarathy, V., Faivre, E., and Hölscher, C. (2011). The diabetes drug liraglutide prevents degenerative processes in a mouse model of Alzheimer's disease. J. Neurosci. 31, 6587-6594. doi: 10.1523/JNEUROSCI.0529-11.2011

Mohamed, L. A., Qosa, H., and Kaddoumi, A. (2015). Age-related decline in brain and hepatic clearance of amyloid-beta is rectified by the cholinesterase inhibitors donepezil and rivastignnine in rats. ACS Chem. Neurosci. 6, 725-736. doi: 10.1021/acschemneuro.5b00040

Moloney, A. M., Griffin, R. J., Timmons, S., O’Connor, R., Ravid, R., and O’Neill, C. (2010). Defects in IGF-1 receptor, insulin receptor and IRS-1/2 in Alzheimer's disease indicate possible resistance to IGF-1 and insulin signalling. Neurobiol. Aging 31, 224-243. doi: 10.1016/j.neurobiolaging.2008.04.002

Nygaard, H. B., van Dyck, C. H., and Strittmatter, S. M. (2014). Fyn kinase inhibition as a novel therapy for Alzheimer's disease. Alzheimers Res. Ther. 6:8 doi: $10.1186 /$ alzrt238

Oldfield, E., and Feng, X. (2014). Resistance-resistant antibiotics. Trends Pharmacol. Sci. 35, 664-674. doi: 10.1016/j.tips.2014.10.007

Ozer, E. O., Tan, O. U., Ozadali, K., Kucukkilinc, T., Balkan, A., and Ucar, G. (2013). Synthesis, molecular modeling and evaluation of novel N '-2-(4benzylpiperidin-/piperazin-1-yl)acylhydrazone derivatives as dual inhibitors for cholinesterases and A beta aggregation. Bioorg. Med. Chem. Lett. 23, 440-443. doi: 10.1016/j.bmcl.2012.11.064

Palmer, A. M. (2011). Neuroprotective therapeutics for Alzheimer's disease: progress and prospects. Trends Pharmacol. Sci. 32, 141-147. doi: 10.1016/j.tips.2010.12.007

Pérez, V., Marco, J. L., Férnandez-Alvarez, E., and Unzeta, M. (1999). Relevance of benzyloxy group in 2-indolyl methylamines in the selective MAO-B inhibition. Br. J. Pharmacol. 127, 869-876. doi: 10.1038/sj.bjp.0702600

Prati, F., Uliassi, E., and Bolognesi, M. L. (2014). Two diseases, one approach: multitarget drug discovery in Alzheimer's and neglected tropical diseases. MedChem Comm 5, 853-861. doi: 10.1039/c4md00069b

Rafii, M. S., Walsh, S., Little, J. T., Behan, K., Reynolds, B., Ward, C., et al. (2011). A phase II trial of huperzine A in mild to moderate Alzheimer disease. Neurology 76, 1389-1394. doi: 10.1212/WNL.0b013e318216eb7b

Rochais, C., Lecoutey, C., Gaven, F., Giannoni, P., Hamidouche, K., Hedou, D., et al. (2015). Novel multitarget-directed ligands (MTDLs) with acetylcholinesterase (AChE) inhibitory and serotonergic subtype 4 receptor (5-HT4R) agonist activities as potential agents against Alzheimer's disease: the design of donecopride. J. Med. Chem. 58, 3172-3187. doi: 10.1021/acs.jmedchem.5b00115

Rosini, M., Simoni, E., Bartolini, M., Tarozzi, A., Matera, R., Milelli, A., et al. (2011). Exploiting the lipoic acid structure in the search for novel multitarget ligands against Alzheimer's disease. Eur. J. Med. Chem. 46, 5435-5442. doi: 10.1016/j.ejmech.2011.09.001

Russo, O., Cachard-Chastel, M., Riviere, C., Giner, M., Soulier, J.-L., Berthouze, M., et al. (2009). Design, synthesis, and biological evaluation of new 5-HT(4) receptor agonists: application as amyloid cascade modulators and potential therapeutic utility in Alzheimer's disease. J. Med. Chem. 52, 2214-2225. doi: $10.1021 /$ jm801327q

Samadi, A., de los Ríos, C., Bolea, I., Chioua, M., Iriepa, I., Moraleda, I., et al. (2012). Multipotent MAO and cholinesterase inhibitors for the treatment of Alzheimer's disease: synthesis, pharmacological analysis and molecular modeling of heterocyclic substituted alkyl and cycloalkyl propargyl amine. Eur. J. Med. Chem. 52, 251-262. doi: 10.1016/j.ejmech.2012.03.022

Schrijvers, E. M. C., Witteman, J. C. M., Sijbrands, E. J. G., Hofman, A., Koudstaal, P. J., and Breteler, M. M. B. (2010). Insulin metabolism and the risk of Alzheimer disease the rotterdam study. Neurology 75, 1982-1987. doi: 10.1212/WNL.0b013e3181ffe4f6

Sirota, M., Dudley, J. T., Kim, J., Chiang, A. P., Morgan, A. A., Sweet-Cordero, A., et al. (2011). Discovery and preclinical validation of drug indications using compendia of public gene expression data. Sci. Transl. Med. 3:96ra77. doi: 10.1126/scitranslmed.3001318

Steindl, T. M., Schuster, D., Laggner, C., and Langer, T. (2006). Parallel screening: A novel concept in pharmacophore modeling and virtual screening. J. Chem. Inf. Model. 46, 2146-2157. doi: 10.1021/ci6002043

Stryjewski, M. E., Potgieter, P. D., Li, Y.-P., Barriere, S. L., Churukian, A., Kingsley, J., et al. (2012). TD-1792 versus vancomycin for treatment of complicated skin and skin structure infections. Antimicrob. Agents Chemother. 56, 5476-5483. doi: 10.1128/AAC.00712-12

Tang, H., Zhao, L.-Z., Zhao, H.-T., Huang, S.-L., Zhong, S.-M., Qin, J.K., et al. (2011). Hybrids of oxoisoaporphine-tacrine congeners: novel acetylcholinesterase and acetylcholinesterase-induced beta-amyloid aggregation inhibitors. Eur. J. Med. Chem. 46, 4970-4979. doi: 10.1016/j. ejmech.2011.08.002

Tyagi, A., Gupta, S., Pandey, A., and Mohan, C. G. (2010). Alzheimer's disease multi-target directed inhibitor design using sequential virtual screening techniques. Curr. Res. Inf. Pharm. Sci. 11, 29-32. Available online at: http:// www.niper.ac.in/29_crips.pdf

Vassar, R. (2014). BACE1 inhibitor drugs in clinical trials for Alzheimer's disease. Alzheimer's Res. Ther. 6, 89-89. doi: 10.1186/s13195-014-0089-7

Wang, L., Ma, C., Wipf, P., Liu, H., Su, W., and Xie, X.-Q. (2013). Target hunter: an in silico target identification tool for predicting therapeutic potential of small organic molecules based on chemogenomic database. Aaps J. 15, 395-406. doi: 10.1208/s12248-012-9449-z

Weinreb, O., Amit, T., Bar-Am, O., and Youdim, M. B. H. (2010). Rasagiline: a novel anti-parkinsonian monoamine oxidase-B inhibitor with neuroprotective activity. Prog. Neurobiol. 92, 330-344. doi: 10.1016/j.pneurobio.2010. 06.008

Wilkinson, D. G., Francis, P. T., Schwam, E., and Payne-Parrish, J. (2004). Cholinesterase inhibitors used in the treatment of Alzheimer's disease the relationship between pharmacological effects and clinical efficacy. Drugs Aging 21, 453-478. doi: 10.2165/00002512-200421070-00004

Wisniewski, T., and Goñi, F. (2014). Immunotherapy for Alzheimer's disease. Biochem. Pharmacol. 88, 499-507. doi: 10.1016/j.bcp.2013.12.020

Xing, S.-H., Zhu, C.-X., Zhang, R., and An, L. (2014). Huperzine a in the treatment of Alzheimer's disease and vascular dementia: a meta-analysis. Evid. Based Complement. Alternat. Med. 2014, 363985-363985. doi: 10.1155/2014/363985

Xu, S. S., Gao, Z. X., Zheng, W., Du, Z. M., Xu, W. A., Yang, J. S., et al. (1995). Efficacy of tablet huperzine-a on memory, cognition, and behavior in Alzheimers-disease. Acta Pharmacol. Sin. 16, 391-395.

Yogev-Falach, M., Amit, T., Bar-Am, O., and Youdim, M. B. H. (2003). The importance of propargylamine moiety in the anti-Parkinson drug rasagiline and its derivatives for MAPK-dependent amyloid precursor protein processing. FASEB J. 17, 2325. doi: 10.1096/fj.03-0078fje

Youdim, M. B. H. (2006). The path from anti Parkinson drug selegiline and rasagiline to multi-functional neuroprotective anti Alzheimer drugs ladostigil and M30. Curr. Alzheimer Res. 3, 541-550. doi: 10.2174/1567205067790 25288

Youdim, M. B. H. (2013). Multi target neuroprotective and neurorestorative anti-Parkinson and anti-Alzheimer drugs ladostigil and m30 derived from rasagiline. Exp. Neurobiol. 22, 1-10. doi: 10.5607/en.2013.22.1.1

Youdim, M. B. H., Finberg, J. P. M., Levy, R., Sterling, J., Lerner, D., Berger-Paskin, T., et al. (1995). R-Enantiomers of N-Propargyl-Aminoindan Compounds, their Preparation and Pharmaceutical Compositions Containing Them. U.S. Patent No: US5457133 A

Youdim, M. B. H., Gross, A., and Finberg, J. P. M. (2001). Rasagiline $\mathrm{N}$-propargyl-1R(+)-aminoindan, a selective and potent inhibitor of mitochondrial monoamine oxidase B. Br. J. Pharmacol. 132, 500-506. doi: 10.1038/sj.bjp.0703826

Youdim, M. B. H., Maruyama, W., and Naoi, M. (2005). Neuropharmacological, neuroprotective and amyloid precursor processing properties of selective MAO-B inhibitor antiparkinsonian drug, rasagiline. Drugs Today 41, 369-391. doi: 10.1358/dot.2005.41.6.893613

Zheng, H., Fridkin, M., and Youdim, M. (2014). From single target to multitarget/network therapeutics in Alzheimer's therapy. Pharmaceuticals 7, 113-135. doi: 10.3390/ph7020113

Zheng, H., Fridkin, M., and Youdim, M. B. H. (2010a). Site-activated chelators derived from anti-parkinson drug rasagiline as a potential safer and more 
effective approach to the treatment of Alzheimer's disease. Neurochem. Res. 35, 2117-2123. doi: 10.1007/s11064-010-0293-1

Zheng, H., Gal, S., Weiner, L. M., Bar-Am, O., Warshawsky, A., Fridkin, M., et al. (2005). Novel multifunctional neuroprotective iron chelatormonoamine oxidase inhibitor drugs for neurodegenerative diseases: in vitro studies on antioxidant activity, prevention of lipid peroxide formation and monoamine oxidase inhibition. J. Neurochem. 95, 68-78. doi: 10.1111/j.14714159.2005.03340.x

Zheng, H., Youdim, M. B. H., and Fridkin, M. (2010b). Site-activated chelators targeting acetylcholinesterase and monoamine oxidase for Alzheimer's therapy. ACS Chem. Biol. 5, 603-610. doi: 10.1021/cb900264w
Conflict of Interest Statement: The authors declare that the research was conducted in the absence of any commercial or financial relationships that could be construed as a potential conflict of interest.

Copyright () 2016 Hughes, Nikolic and Ramsay. This is an open-access article distributed under the terms of the Creative Commons Attribution License (CC $B Y)$. The use, distribution or reproduction in other forums is permitted, provided the original author(s) or licensor are credited and that the original publication in this journal is cited, in accordance with accepted academic practice. No use, distribution or reproduction is permitted which does not comply with these terms. 